\title{
Comparative Analysis of Single Exponential Smoothing and Holt's Method for Quality of Hospital Services Forecasting in General Hospital
}

\author{
Rachmat $^{1}$, Suhartono ${ }^{2}$ \\ ${ }^{1}$ Department of Electrical Engineering, Politeknik Informatika Nasional \\ ${ }^{2}$ Department of Electrical Engineering, Universitas Negeri Makassar
}

\begin{tabular}{l}
\hline \hline Article Info \\
\hline Article history: \\
Received Jun 26, 2020 \\
Revised Aug 10, 2020 \\
Accepted Aug 17, 2020 \\
\hline
\end{tabular}

Keywords:

Comparative Analysis

Single Exponential Smoothing

Holt's Method

Mean Absolute Deviation

MAD

Hospital services

\begin{abstract}
The quality health service is one of the basic necessities of any person or customer. To predict the number of goods can be done in a way predicted. The comparison method of Single Exponential Smoothing and Holt's method is used to predict the accuracy of inpatient services will be back for the coming period. Single Exponential Smoothing the forecasting methods used for data stationary or data is relatively stable. Holt's method is used to test for a trend or data that has a tendency to increase or decrease in the long term. The outcome of this study is the Single Exponential Smoothing method is more precise than Holt's method because of the history of hospitalized patients who do not experience an increase or no trend. In addition, the percentage of error (the difference between the actual data with the forecast value) and Mean Absolute Deviation (MAD) to calculate the forecast error obtained from the Single Exponential Smoothing method is smaller compared to Holt's method.
\end{abstract}

This is an open access article under the CC BY-SA license.

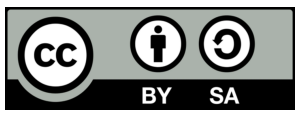

\section{Corresponding Author:}

Rachmat

Department of Electrical Engineering, Politeknik Informatika Nasional

Suhartono

Department of Electrical Engineering, Universitas Negeri Makassar

Sultan Alauddin Street No. 250, Makassar, South Sulawesi, Indonesia

Email: rachmat27udinus@gmail.com, suhartono@unm.ac.id

\section{INTRODUCTION}

Utilization of services hospitalization is the most important thing in the hospital for using forecasting hospital can predict how many patients will come back and eventually affect the continuity of the development of the hospital itself can not be separated from the interaction of three main elements, namely customer service officer and management [1]. Because of these interactions, raised the output of a process of delivering services in the form of service to be revalued by its customers as a quality and satisfactory service [2]. Understanding the needs of patients is an important thing that affects patient satisfaction. Patients who are satisfied is a very valuable asset, because the patient satisfaction will provide information to people close (relatives, family and neighbor) [3], that the services provided by the public hospitals very satisfying. Hospital as a referral service units of health care units under it such as: health center, private 
physician practices, pharmacies and others, are also part of the output of hospital services required to foster good cooperation and mutual benefit with emphasis on patient satisfaction[4]. By using the method of Single Exponential Smoothing and Holt's method, we can estimate the number of patients who will return to the hospital [5].

If the customer chooses a quality hospital, the main factor that influences his selection is the service of the officers. They will choose a hospital that they think can provide the best service. A sufferer can assess the services of a hospital, although sometimes it is difficult to accurately assess the care and nursing techniques given to him. The use of inpatient services which is the most important thing in the hospital because using hospital forecasting can predict how many patients will return and in the end it affects the continuity of the development of the hospital itself is inseparable from the interaction of three main elements, namely customers, service personnel and management. Because of this interaction, the output of a service delivery process arises in the form of services that will be reassessed by customers as a quality and satisfying service. Understanding the patient's needs is an important thing that affects patient satisfaction.

According to [6]-[8], there are some common calculations used to calculate the total forecast error. This calculation can be used to compare forecasting models different, also to supervise forecasting, to make sure the forecast is running well. Forecasting models carried out are then validated using a number of indicators. Commonly used indicators are average absolute deviation or called Mean Absolute Deviation (MAD), and average squares smallest or also known as Mean Square Error (MSE).

Mean Squared Error (MSE) is another method of evaluating forecasting method. Each error or remainder is squared. Then add up and add to the number of observations. This approach governs the large forecast errors due to errors - they are squared. That method pays off moderate errors are likely to be better for small mistakes, but sometimes make a big difference [9], [10]. Meanwhile, the Sum Square Error (SSE) is a statistical method used to measure the difference between the total value and the value achieved. The term SSE is also known as the Summed Square of Residuals. SSE is used to measure the difference between the data obtained and the prediction model that has been done previously [11].

The original error value is not averaged as a measure of the size of the error, with a variation of positive and negative values, so that if the error value is added together becomes small, the result is that the deviation from the actual forecast is large as if it looks small because if the error is just added up, the error is large positive will be eliminated by a large negative error. To avoid this, the error needs to be made into an absolute number or squared and then averaged.

\section{RESEARCH METHOD}

\subsection{Single Exponential Smoothing}

Single Exponential Smoothing method is a method that shows weighting decreases exponentially with observed values older [12]. Value is later given relatively greater weight than the value of observation is longer [13]. This method gives an exponential weighted moving average of all values of previous observations[14]. In this method is not affected by this trend and the season. The equation is as follows:

where:

$$
\hat{Y} t+1=\alpha Y t+(1-\alpha) \hat{Y} t
$$

$$
\begin{aligned}
& \hat{\mathrm{Y}} \mathrm{t}+1=\text { value forecast for the next period } \\
& \mathrm{Yt}=\text { demand for period } \mathrm{t} \\
& \hat{\mathrm{Y}} \mathrm{t}=\text { forecast value for period } \mathrm{t} \\
& \alpha=\text { smoothing weighting factor }(0<\alpha<1)
\end{aligned}
$$

In the equation (1), to predict the value of the next period, the necessary demand data from previous periods and forecasting the previous period 


\subsection{Holt's Method}

This method is often referred to Holt's Method [15]. This method is used when the demand is influenced trend but is not influenced by the seasons [16], [17]. According Makridakis, Wheelwright and Hyndman this method paved the trend values with different parameters of the parameters used in the original series [18]. To forecast the demand in the next period, should be known to forecast the level or the value of new refining and estimate trends [19]. Here's the equation to determine the level forecast and estimates of the trend:

$$
\begin{aligned}
L t & =\alpha Y t+(1-\alpha)(L t-1+T t-1) \\
T t & =\beta(L t-L t-1)+(1-\beta) T t-1
\end{aligned}
$$

In the equation (2), the value of smoothing all $t$ need the data requests that all $t$, the value of smoothing the previous period and the value of the previous trend [20]. Having in mind the value of smoothing all $t$, then you can get the value $t$ trend that all equation (3) [21], [22]. The forecast level and trend estimates have been obtained, then can know the real demand forecasting period in the future with the following equation:

where:

$$
\hat{\mathrm{Y}} t+p=L t+p T t
$$

$$
\begin{aligned}
& L t=\text { the estimated level (new smoothing value) } \\
& Y t=\text { demand in period } \mathrm{t} \\
& T t=\text { trend estimate for the period } \mathrm{t} \\
& \hat{Y} t+p=\text { the forecast for future periods } \mathrm{p} \\
& P=\text { the number of periods to forecast future } \\
& \alpha=\text { smoothing weighting factor for the level }(0<\alpha<1) \\
& \beta=\text { a weighting factor for the trend smoothing }(0<\beta<1)
\end{aligned}
$$

\subsection{Mean Absolute Deviation (MAD)}

MAD is one equation for calculating the forecast error. MAD is the median absolute deviation. Its use is by calculating all the deviation (difference between demand and forecasting) and absolutize all negative into a positive value is then divided by the amount of data that there is an equation (5). The equation is as follows:

where:

$$
M A D n=(\operatorname{Sum}(t=1 \text { to } n)[A t]) / n
$$

$A t=$ absolute deviation for period $t=|E t|$

$n=$ amount of data

To calculate Et, required data is present period is reduced by the present value of the forecast period as specified in the equation (6):

$$
E t=Y t-\hat{Y} t
$$

where:

$$
\begin{aligned}
& E t=\text { forecast error in period } t \\
& Y t=\text { the real value in period } t \text { (request) } \\
& \hat{Y} t=\text { forecast value for period } t
\end{aligned}
$$

\section{RESULTS AND DISCUSSION}

\subsection{Analysis}

The dataset is processed using the application of Olives to predict or forecast time series against the re-utilization of inpatient services by using a dataset from 2000 to 2015, hospital and (1) hospital Makassar. 


\subsection{Sample and Population}

- Population

The population was inpatients more than one day at the General Hospital Makassar.

- $\quad$ Sample

The number of samples to be taken using the following equation

$$
n=\frac{N \cdot Z^{2} \cdot p q}{d^{2}(N-1)+Z^{2} \cdot p \cdot q}
$$

where:

$\mathrm{n}=$ large sample

$\mathrm{N}=$ Large Population (2157 inpatients)

$\mathrm{P}=$ The proportion of inpatients $=0.5$

$\mathrm{q}=1-\mathrm{P}=1-0,5=0,5$

$\mathrm{D}=$ The level of accuracy is used 0.1

$\mathrm{Z}=$ Standard deviation is appropriate, it is used in accordance with the degree of prosperity 1.96 or $95 \%$

$$
\begin{gathered}
n=\frac{2157 \cdot 1,96^{2} \cdot 0,5 \cdot 0,5}{0,1^{2}(2157-1)+1,96^{2} \cdot 0,5 \cdot 0,5} \\
n=\frac{207,158,2800}{962,556} \\
n=2152,1686=2152 \text { Inpatients }
\end{gathered}
$$

\subsection{Methods of Analysis}

where:

$$
Y=B 0+B 1 X 1+B 2 X 2+B 3 X 3+B 4 X 4+B 5 X 5+e i
$$

$$
\begin{aligned}
& Y=\text { Interests reuse inpatient services } \\
& X 1=\text { Medical facilities and medicine (Availability) } \\
& X 2=\text { Responsiveness (Responsiveness) } \\
& X 3=\text { Reliability and accuracy (Reliability) } \\
& X 4=\text { Assurance (Assurance) } \\
& X 5=\text { Concern (Empathy) } \\
& B 0=\text { constants } \\
& B 1-B 5=\text { The regression coefficient of } X \\
& e i=\text { Error term (error factor) }
\end{aligned}
$$

- Hospital in Makassar

The value of Mean Absoulute Error (MAE) with Alpa $=0.2$, the error value is greater than using Alpa $=0.5$, while the Sum Squared Error (SSE) value with the value of Alpha $=0.2$ is greater than that of Alpa $=0.5$ thus with the Mean Sqaured Error (MSE) with Alpa $=0.2$ the value is greater using Alpha 0.5

Table 1. Hospital in Makassar

\begin{tabular}{|c|c|c|c|}
\hline & MAE & SSE & MSE \\
\hline Alpha $=\mathbf{0 . 2}$ & 215.300667 & 9922953.594179 & 162671.370396 \\
\hline Alpha $=\mathbf{0 . 5}$ & 126.746436 & 6723962.7198835 & 110228.897047 \\
\hline
\end{tabular}


Figure 2 illustrates the results using the Zaitun application tool by displaying the prediction results using Single Exponential Smoothing with And Holts method by combining these two methods, the results are as shown in the following figure.

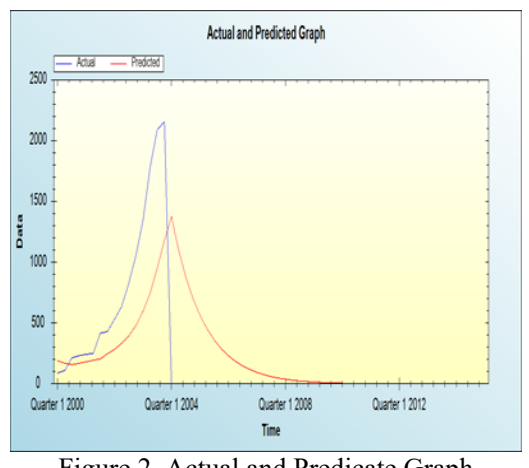

Figure 3 displays the previous graph using both methods so that the results can be shown in the following figure where the residual value of the graph can be seen in the following figure.

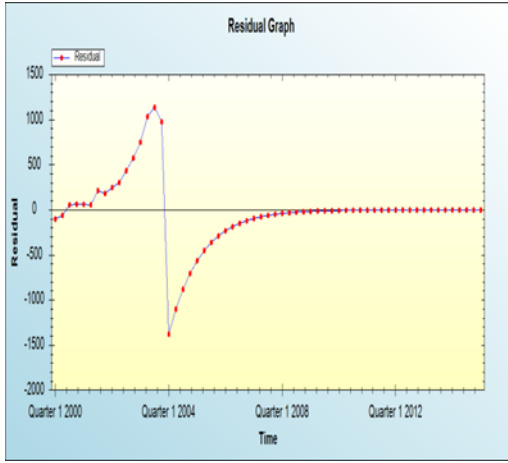

Figure 3. Residual Graph

- Hospital in Makassar (1)

The results of the use of these two methods can be concluded that services for inpatient services are higher in private hospitals compared to public hospitals, it can be seen from the comparison of Alpha in each table, it turns out that table number 2 is higher than Table number 1.

Table2. Hospital in Makassar

\begin{tabular}{|c|c|c|c|}
\hline & MAE & SSE & MSE \\
\hline Alpha $=\mathbf{0 . 2}$ & 57.188027 & 513266.581997 & 8414.206262 \\
\hline Alpha $=\mathbf{0 . 5}$ & 26.209626 & 267712.070253 & 4388.722463 \\
\hline
\end{tabular}

Figure 4 displays the previous graph using both methods so that the results can be shown in the following figure where the residual value of the graph can be seen in the figure.

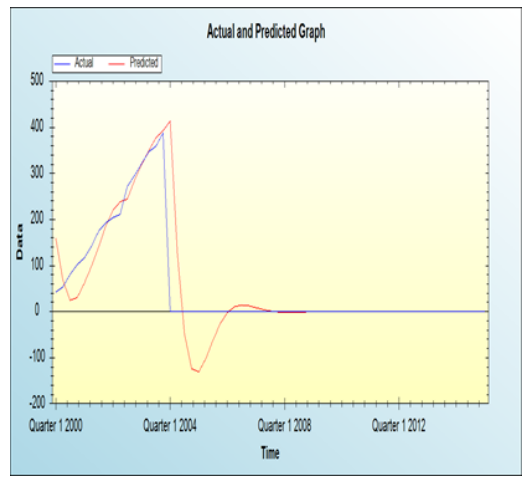

Figure4. Actual and Predicate Graph 
Figure 5 displays the previous graph using both methods so that the results can be shown in the following figure where the residual value of the graph can be seen in the figure.

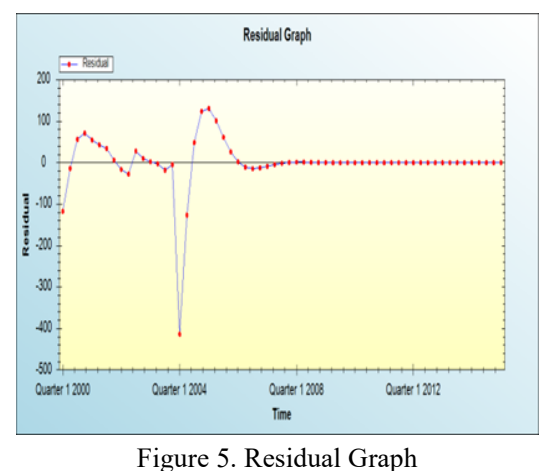

\subsection{Discussion}

The comparison results from Table 1 and Table 2 with the same Alpha value, namely $=2$, it turns out that table 2 is greater for patients who come back for hospitalization as compared to table 1 . Where table 3 with an alpha of 0.2 obtained an MSE (Mean Squared error) of $=162671.370396$ this means that more research experiments use the above method.

Table 3. Comparison of Alpha $=0.2$

\begin{tabular}{|c|l|l|}
\hline \multicolumn{1}{|c|}{ (2) } & \multicolumn{1}{|c|}{ (1) } \\
\hline $\boldsymbol{\alpha}$ & $\boldsymbol{\alpha}=\mathbf{0 . 2}$ & $\boldsymbol{\alpha}=\mathbf{0 . 2}$ \\
\hline $\mathrm{MAE}$ & 215.300667 & 57.188027 \\
\hline $\mathrm{SSE}$ & 9922953.594179 & 513266.581997 \\
\hline $\mathrm{MSE}$ & 162671.370396 & 8414.206262 \\
\hline
\end{tabular}

And also, with the value of Alpha $=0.5$, it is shown in table 2 that inpatient services were greater than the return of patients in table 1. Whereas in table 4 using alpha 0.5 where the Mean Squared Error (MSE) is obtained of 110228.897047 , it is better to also use the above method.

Table 4. Comparison of Alpha $=0.5$

\begin{tabular}{|c|c|c|}
\hline & (2) & (1) \\
\hline$\alpha$ & $\alpha=0.5$ & $\alpha=0.5$ \\
\hline MAE & 126.746436 & 26.209626 \\
\hline SSE & 6723962.7198835 & 267712.070253 \\
\hline MSE & 110228.897047 & 4388.722463 \\
\hline
\end{tabular}

\section{CONCLUSION}

Based on the results Discussion and Analysis can be concluded that with $\alpha=0.2$ at (1) hospital MAE 57.188027 better than MAE hospital Makassar, while the SSE (1) hospital is better that 513266.581997 and the MSE is also better that is equal to 8414.206262. for $\alpha=0.5$ (1) hospital MAE 26.209626 better than MAE hospital for SSE 267712.070253 also better than (1) hospital while MSE better at 4388.722463. So, it can be concluded that the Single Exponential Smoothing is more appropriate than the Holt method because the history of inpatients has not increased or there is no trend. In addition, the percentage error and Mean Absolute Deviation for calculating the forecast error obtained from the Single Exponential Smoothing method are smaller than the Holt method.

\section{REFERENCES}

[1] S. Tsumoto and S. Hirano, "Analytics for hospital management," ACM Int. Conf. Proceeding Ser., vol. 07-09Ocob, 2015. 
[2] E. C. Mavratzotis, C. J. Stathi, and S. P. Papanastasiou, "Interactive doctor-patient system of the pain relief cabinet," p. 1, 2008.

[3] S. Haldar, S. R. Mishra, M. Khelifi, A. H. Pollack, and W. Pratt, "Opportunities and design considerations for peer support in a hospital setting,” Conf. Hum. Factors Comput. Syst. - Proc., vol. 2017-May, pp. 867-879, 2017.

[4] Y. Kurniawan, "Knowledge management model for hospital (a case study approach: Focus on knowledge gathering process)," ACM Int. Conf. Proceeding Ser., no. 9, pp. 112-116, 2017.

[5] S. R. Mishra et al., "Supporting collaborative health tracking in the hospital: Patients' perspectives," Conf. Hum. Factors Comput. Syst. - Proc., vol. 2018-April, pp. 1-14, 2018.

[6] H. Konno and H. Yamazaki, "Mean-Absolute Deviation Portfolio Optimization Model and Its Applications to Tokyo Stock Market," Manage. Sci., vol. 37, no. 5, pp. 519-531, May 1991.

[7] H. Konno and T. Koshizuka, "Mean-absolute deviation model," IIE Trans. (Institute Ind. Eng., vol. 37, no. 10, pp. 893-900, Oct. 2005.

[8] C. Willmott and K. Matsuura, "Advantages of the mean absolute error (MAE) over the root mean square error (RMSE) in assessing average model performance," Clim. Res., vol. 30, no. 1, pp. 79-82, Dec. 2005.

[9] H. C. Shin and A. H. Sayed, "Mean-Square Performance of a Family of Affine Projection Algorithms," IEEE Trans. Signal Process., vol. 52, no. 1, pp. 90-102, Jan. 2004.

[10] A. P. Slavia, E. Sutoyo, and D. Witarsyah, "Hotspots Forecasting Using Autoregressive Integrated Moving Average (ARIMA) for Detecting Forest Fires," in 2019 IEEE International Conference on Internet of Things and Intelligence System (IoTaIS), 2019, pp. 92-97.

[11] P. Guan, D. S. Huang, and B. Sen Zhou, "Forecasting model for the incidence of hepatitis A based on artificial neural network," World J. Gastroenterol., vol. 10, no. 24, pp. 3579-3582, Dec. 2004.

[12] I. Tolstikova, M. Shubinskiy, and B. Nizomutdinov, "Hospital websites as a tool of health service," ACM Int. Conf. Proceeding Ser., vol. 2015-Novem, pp. 170-173, 2015.

[13] S. Tonjang and N. Thawesaengskulthai, "Patient food delivery error in the hospital: A case study in Thailand," ACM Int. Conf. Proceeding Ser., pp. 151-156, 2019.

[14] M. M. Ulkhaq et al., "Evaluating hospital service quality: A combination of the AHP and TOPSIS," ACM Int. Conf. Proceeding Ser., pp. 117-124, 2018.

[15] C. Klangrahad, "Evaluation of Thailand's regional hospital efficiency: An application of data envelopment analysis," ACM Int. Conf. Proceeding Ser., vol. Part F1312, pp. 104-109, 2017.

[16] D. Risteski, A. Kulakov, and D. Davcev, "Single exponential smoothing method and neural network in one method for time series prediction," in 2004 IEEE Conference on Cybernetics and Intelligent Systems, 2004, pp. 740-744.

[17] E. Cadenas, O. A. Jaramillo, and W. Rivera, "Analysis and forecasting of wind velocity in chetumal, quintana roo, using the single exponential smoothing method," Renew. Energy, vol. 35, no. 5, pp. 925-930, May 2010.

[18] S. Makridakis, S. Wheelwright, and R. J. Hyndman, "Forecasting: Methods and Applications, 3rd Edition," John Wiley \& Sons, 1998.

[19] M. Ordu, E. Demir, and C. Tofallis, "A comprehensive modelling framework to forecast the demand for all hospital services,” Int. J. Health Plann. Manage., vol. 34, no. 2, pp. e1257-e1271, Apr. 2019.

[20] S. Gelper, R. Fried, and C. Croux, "Robust forecasting with exponential and Holt-Winters smoothing," $J$. Forecast., vol. 29, no. 3, p. n/a-n/a, Apr. 2009.

[21] E. S. Gardner and D. G. Dannenbring, "FORECASTING WITH EXPONENTIAL SMOOTHING: SOME GUIDELINES FOR MODEL SELECTION,” Decis. Sci., vol. 11, no. 2, pp. 370-383, Apr. 1980.

[22] E. M. de Oliveira and F. L. Cyrino Oliveira, "Forecasting mid-long term electric energy consumption through bagging ARIMA and exponential smoothing methods," Energy, vol. 144, pp. 776-788, Feb. 2018. 